\title{
The Effect of Pre-Incision Urethral Plate Width and Granular Width on the Outcome of Tabularized Incised Urethral Plate Repair Surgery in Distal Penile Hypospadias, A Prospective Study
}

\author{
Diaa-Eldin Taha*, Mohamed Galal and Tarek Abdelbaky \\ Urology department, Kafer Elsheikh University, Egypt
}

*Corresponding author: Diaa Eldin Taha, Lecturer of urology, Department of

Urology Faculty of medicine, Kafrelsheikh University, Kafrelsheikh, Egypt.

Received Date: March 21, 2020

Published Date: April 30, 2020

\begin{abstract}
Objective: To determine the cosmetic and functional outcomes of hypospadias repair in relation to the width of the urethral plate in addition to granular width and configuration.

Materials and methods: The study was a prospective evaluation of patients operated for hypospadias. The urethral plate width (UPW) and glans width (GW) of the patients were measured preoperatively using standard calipers. The width of the urethral plate was correlated to the cosmetic outcome (using hypospadias objective penile evaluation [HOPE]) and functional outcome (using the urinary stream) of hypospadias repair. All patients were managed via the same technique using Snodgrass tabularized incised plate repair (TIP). All operations were performed by a single surgeon. All intaoperative data were recorded. All patients were followed up for 1 year. Success was defined as slit shaped meat us at the tip of the glans with no stenosis, fistula or diverticulum.
\end{abstract}

Results: All 38 patients were evaluated at 6 months and 1 year follows up. The mean age at surgery was $4.5 \pm 2.1$ years. Overall, the mean \pm SD of UPW was $10.92 \pm 1.24 \mathrm{~mm}$. a 24 patients (61.5\%) (Group A) had a urethral plate width of less than $8 \mathrm{~mm}$ while 14 patients (35.9\%) (group B) had a urethral plate width greater or equal to $8 \mathrm{~mm}$. the mean \pm SD of GW was $9.52 \pm 1.56 \mathrm{~mm}$. Success was documented in 36/38 patients (94.3\%). The only complication was Fistula in two patients $(6.7 \%)$, glans dehiscence in three patients $(10 \%)$. Success rate was not statistically different in correlation of UPW and GW ( $\mathrm{p}=0.5)$. The only statistically significant difference between all patients was a longer operative time in the patients with deficient urethral plate compared to others with adequate urethral plate $(\mathrm{p}=0.005)$. The urinary stream was straight in 32 boys and sprayed in 6 . Overall, mean \pm SD HOPE score was $39.1 \pm 8.83$. A significant correlation found between the cosmetic outcome of the two groups and HOPE score $(\mathrm{p}=0.06)$.

Conclusion: The pre-incision urethral plate width and granular width was not correlated with the TIP outcome. A better HOPE score is associated with wide urethral plate.

Keywords: Hypospadias; Urethral plate; Tabularized incised plate repair (TIP); Hypospadias objective penile evaluation

\section{Introduction}

Dating the final 2 decades, tabularized incised plate procedure (TIP) for repair of distal penile hypospadias is the foremost common method at numerous institutions. In any case, a few downsides counting metal and/or neourethral stenosis and the require for standard urethral dilatation have been recorded [1]. The preservation of the urethral plate and the increase in the surface area with healthy epithelium give better outcome [2] TIP is a procedure that is more dependent on urethral plate quality in comparison with other surgical procedures. The plate quality is generally regarded as one of the intrinsic risk factors influencing the outcomes of hypospadias repairs. However, there is currently no clear agreement on the evaluation of the urethral plate [3].The urethral plate width was classified based on an arbitrary 8-mm cutoff value, while groove depth was graded as deep, moderate and shallow. However, is the arbitrary value of $8 \mathrm{~mm}$ suitable for all penis sizes? [4]. Generally, urethral plate width increases with penis size, as the patient grows. It might be more appropriate to evaluate 
urethral plate quality with a parameter scaled with penis size. In recent years, Glans-Urethral Meat us-Shaft score was proposed to classify the severity of hypospadias, providing a concise method for evaluating urethral plate quality $[4,5]$. There is a debate regarding the effect of UPW and GW on the postoperative complications post TIP surgery. Some reports have found that urethral plate (UP) widths $<8 \mathrm{~mm}$ before TIP incision increased urethroplasty complications [6]. While, The UP width before incision did not increase urethroplasty complications [7-9]. Glans size does not correlate with age in patients with hypospadias between 3 and 24 months old, supporting the decision to operate as early as 3 months in some centers [10]. Small glans size, defined as width $<14 \mathrm{~mm}$, is an independent risk factor for urethrocutanous fistula [8]. To address this void, we aimed to answer a question, Is the UPW and GW are a controlling factors for hypospadias outcome as regard the functional and cosmetic outcome?

\section{Materials and Methods}

After approval from Institutional Review Board, we conducted a prospective study that was carried out in Urology department in kafr el sheikh university, between November 2018 and November 2019. A total of 60 children diagnosed with distal penile hypospadias were included. Inclusion criteria were, distal penile hypospadias, primary, uncircumcised, and no or mild chordee (less than $30^{\circ}$ ), aged $<10$ years, No associated syndromes and boys able and willing to comply with follow up schedule. We excluded boys who were recurrent, circumcised, with severe chordee. written consent with detailed description of the operation and expected complications was explained and signed from the parents. All operations were performed by single pediatric urologists. Preoperative IV antibiotic prophylaxis was given. A circumferential sub coronal incision is made proximal to the hypospadiac urethral meat us. The penis is degloved. A bilateral longitudinal incision was made along the urethral plate to prepare the granular wings. The flap was obtained from the inner dartos muscle and sutured overlying the incision line with 6/0 vicryl. The flap width and length were differing in every case according to the location of the meat us, urethral plate characteristics and depth of the midline incision. Urethroplasty was performed using 6/0 Vicryl continuous subcuticular then interrupted sutures and 2nd layer cover using dartos fascia flap. Granular approximation was done with 6/0 Vicryl. 8F stent was kept for 7-10 days. All patients were routinely followed up for cosmetic and functional results at 3 months intervals. By routine examination of the external genitalia, evaluation of the voiding symptoms, uroflowmetery study was performed if possible and it was repeated when the voided volume was insufficient or when the result was inconsistent with the physical examination and history. Overall acceptable cosmetic appearance of the penis was decided according to the slit like appearance of the neo-meat us, the straight position of the penis and this cosmetic aspect was judged by an independent blinded observer. Hypospadias Objective Penile Evaluation (HOPE) is considered a valuable tool for assessing the outcome [11].

\section{Statistical Analysis}

Statistical analysis was performed with IBM Statistical Package for Social Sciences. IBM SPSS Statistics for Windows (version 22.0. Armonk, NY) was used to evaluate multiple steps. Significance level was set to $\mathrm{p}<0.05$. Internal consistency reliability was tested using Cronbach's $\alpha$, and test-retest reliability was assessed with the Wilcox on signed rank test. For concurrent external validity, Spearman rank correlation was used. For values $>0.70$, it was assumed that there was sufficient consistency and reliability.

\section{Results}

1. All 30 patients were evaluated at 1 year of follow up. Mean age at surgery was $4.5 \pm 2.1$ years.

2. Of the 30 patients who had their distal hypospadias repaired using TIP, seven patients (23.3\%) had glanular hypospadias, nine patients (30\%) had coronal hypospadias and 14 patients (46.7\%) had distal penile hypospadias (Table 1).

Table 1: Patients Demographics.

\begin{tabular}{|c|c|c|c|}
\hline & & $\begin{array}{c}\text { Distal } \\
\text { Hypospadias }(\mathrm{N}=38)\end{array}$ & $\mathbf{P}$ \\
\hline \multicolumn{2}{|c|}{ Age in years (mean \pm SD) } & $4.5 \pm 2.1$ & 0.59 \\
\hline \multicolumn{2}{|c|}{ Weight $($ mean \pm SD) } & $26.16 \pm 13.16$ & \\
\hline \multicolumn{2}{|c|}{ Operative time (mean \pm SD) } & $76.60 \pm 9.8$ & \\
\hline \multirow{3}{*}{ Metal Location } & Granular & $8(21.1 \%)$ & 0.9 \\
\hline & Coronal & $15(38.5 \%)$ & \\
\hline & Midpenile & $15(38.5 .5 \%)$ & \\
\hline \multicolumn{2}{|c|}{ Mean urethral plate width (UPW) } & $4.92 \pm 1.24$ & 0.5 \\
\hline \multirow{2}{*}{$\begin{array}{c}\text { Urethal } \\
\text { Configuration }\end{array}$} & Adequate & $24(80 \%)$ & 0.7 \\
\hline & Hypoplastic & $6(20 \%)$ & \\
\hline $\begin{array}{l}\text { Circumcised } \\
\text { (NO) }\end{array}$ & & $11(36.7 \%)$ & \\
\hline \multicolumn{2}{|c|}{ Mean granular width (GW) } & $9.52 \pm 1.56$ & 0.4 \\
\hline \multirow{2}{*}{$\begin{array}{l}\text { Ventral } \\
\text { Curvature }\end{array}$} & 30-0ct & $2(5.2 \%)$ & 0.21 \\
\hline & $\leq 10$ & $5(18.1 \%)$ & \\
\hline
\end{tabular}

3. Overall, the mean \pm SD of UPW was $10.92 \pm 1.24 \mathrm{~mm}$. a 24 patients (61.5\%) (group A) had a urethral plate width of less than $8 \mathrm{~mm}$ while 14 patients (35.9\%) (group B) had a urethral plate width greater or equal to $8 \mathrm{~mm}$. the mean \pm SD of GW was $9.52 \pm 1.56 \mathrm{~mm}$.

\section{Functional outcome}

1. The average urine flow rates (Qmax) of 38 patients was 7 $\mathrm{ml} / \mathrm{sec}(5.3-10.3)$.

2. A $20(83.3 \%)$ patients in group A have good urinary stream while 12 patients ( $85.7 \%$ ) in group B have good urinary stream.

3. There was a significant correlation between good urinary stream with the mean UPW of the 2 groups $(\mathrm{p}<0.05)$. 


\section{Post-operative complications}

1. Two patients (6.3\%) developed urethrocutanous fistula three patients $(10 \%)$ developed granular dehiscence.

2. Five patients (14.3\%) in group A developed complications while one patients (16.7\%) in group B developed complications.

3. However, no statistical significance found in relation of the complications to the mean UPW or GW of the two groups of patients $(\mathrm{p}=0.5)$.

\section{Cosmetic outcome}

1. The cosmetic outcome was assessed using Hypospadias Objective Penile Evaluation (HOPE), as shown in Table 2 (Table 2).

Table 2: Outcome in correlation to UPW.

\begin{tabular}{|c|c|c|c|c|}
\hline & $\begin{array}{c}\text { UPW } \leq 8 \\
m m(N=24)\end{array}$ & $\begin{array}{c}\text { UPW } \geq 8 \\
m m(N=14)\end{array}$ & $\mathbf{P}$ \\
\hline \multicolumn{2}{|c|}{ No of UC } & $0(0 \%)$ & $3(12.3 \%)$ & 0.2 \\
\hline \multicolumn{2}{|c|}{ Granular dehiscence } & $1(4.2 \%)$ & $2(14.3 \%)$ & 0.6 \\
\hline \multicolumn{2}{|c|}{ Metal stenosis } & $2(8.3 \%)$ & $2(14.3 \%)$ & 0.4 \\
\hline \multicolumn{2}{|c|}{ Slit like urethra } & $20(83.3 \%)$ & $12(85.7 \%)$ & 0.6 \\
\hline \multicolumn{2}{|c|}{ Straight penis } & $20(83.3 \%)$ & $12(85.7 \%)$ & 0.3 \\
\hline \multicolumn{2}{|c|}{$\begin{array}{c}\text { Apparently Normal looking } \\
\text { skin }\end{array}$} & $20(83.3 \%)$ & $12(85.7 \%)$ & 0.6 \\
\hline \multirow[t]{2}{*}{ Metal shape } & Vertical slit & $20(83.3 \%)$ & $12(85.7 \%)$ & 0.3 \\
\hline & Circular & 4 ( $16.7 \%)$ & $1(7.1 \%)$ & \\
\hline \multirow{2}{*}{$\begin{array}{l}\text { Urinary } \\
\text { stream }\end{array}$} & $\begin{array}{l}\text { Single } \\
\text { stream }\end{array}$ & $20(83.3 \%)$ & $12(85.7 \%)$ & 0.6 \\
\hline & Spray & $4(16.7 \%)$ & $2(14.3 \%)$ & \\
\hline \multicolumn{2}{|c|}{$\mathrm{Qmax}($ mean $\pm \mathrm{SD})$} & $8.4 \pm 2.4$ & $10.4 \pm 3.1$ & 0.05 \\
\hline \multicolumn{2}{|c|}{ Hope } & $37.2 \pm 6.4$ & $42.4 \pm 6.1$ & 0.06 \\
\hline
\end{tabular}

2. Overall, mean \pm SD hypospadias objective penile evaluation (HOPE) score was $39.1 \pm 8.83$. Group A patients had a mean HOPE score of $37.2 \pm 6.4$ SD while Group B patients had a mean HOPE score of $42.4 \pm 6.1$ SD.

3. A significant correlation found between the cosmetic outcome of the two groups and HOPE score $(p=0.06)$.

\section{Discussion}

Hypospadias is an extremely common anomaly. There are different procedures that have been described for the adjustment of hypospadias since of the presence of various hypospadias presentations. Be that as it may, no single technique had $100 \%$ satisfactory result [12]. The goals of hypospadias surgery include development of a urethra of sufficient caliber and length, orthotropic meat us at the tip of the glans permitting the patient to void in a straight stream without maddening spreading. Moreover, obtaining a conical glans and rearrangement of the dorsal skin provides a uniform ventral skin cover and correction of penile curvature just to achieve proper sexual intercourse and effectively inseminate [13]. Hypospadias surgery is continuously evolving, since its description by Galen in the first and second centuries AD, to improve a suboptimal functional and cosmetic results. The aim of hypospadias surgery is the creation of a straight penis with a slitlike meat us at the tip of the glans 7. In spite of the recognition of the urethral plate as the tissue distinct from the glans and penile skin that would have formed the urethra and as having a well vascularized connective tissue and its incorporation in hypospadias repair, an objective way of assessing the impact of urethral plate on outcome is yet to be established. Snodgrass in 1994 reported his own technique of tabularized incised plate urethroplasty (TIP) repair for distal hypospadias that gained a widespread use for its perceived simplicity and good cosmetic outcomes in the majority of cases [11]. However, unfortunately, when the urethral plate is narrow the rate of urethrocutaneous fistula, metal/neo-urethral stenosis is increased [12]. In the current study, we evaluated the effect of width of the urethral plate and granular width on outcome of hypospadias repair. Most of our patients had coronal and midpenile hypospadias (38.5\%\%), the same findings by Part et al [14]. The reason for this is not clear but might be explained by the geographical location. Hypospadias Objective Penile Evaluation (HOPE) which assessed the cosmetic outcome, there was a statistical significance correlation $(p=0.06)$. This finding agrees with the result from some previous studies [15]. However, Aboutaleb et al [6] in their study We used $8 \mathrm{~mm}$ in the present study because urethral plate width $8 \mathrm{~mm}$ or greater is essential for creation of adequate neourethra and successful hypospadias repair [16],while, Da Silva et al1 [15] in their study had $41.9 \%$ of their patients in the narrow urethral plate group and $58.1 \%$ in the wide urethral plate group. Comparing both studies, the slight difference in percentages may be explained by the fact that Da Silva used $10 \mathrm{~mm}$ as the dividing line between narrow and wide urethral plates while we used $8 \mathrm{~mm}$ in the current study. Nguyen et al [9] and Aboutaleb et al [6] in their studies also used $8 \mathrm{~mm}$ as the dividing line. Urethral plate of more than $8 \mathrm{~mm}$ is associated with good cosmetic outcome $[16,17]$ On the assessment of the functional outcome, 20 ( $83.3 \%$ ) patients in group A had good urinary stream while twenty patients 12 ( $85.7 \%$ ) in group B had good urinary stream. Statistical analysis showed that there is a statistically significant difference between the 2 groups ( $p$ value of 0.05 ). This agrees with findings of some other studies that concluded that narrow urethral plate is associated with poor functional outcome such as poor urinary stream and complications such as metal stenosis and urethrocutanous fistula [17-19]. However, Nguyen et al and Da Silva et al [15] in their study concluded that width of urethral plate do not affect the functional outcome of hypospadias repair. This is related to the fact that there were confounding variables in their study such as penile size, glans shape and vascularity of the prepuce which were not separately analyzed. We did not assess penile size, glans shape and vascularity of the prepuce in the current study. There are a diversity in the complications following hypospadias repair. It ranges from $6-30 \%[20,21]$. The most common complication we recorded was urethrocutanous fistula. These differences in complication rates may be explained by the differences in surgical expertise due to low 
volume of hypospadias repairs done per year in our setting. The rate of urethrocutanous fistula in our study is not correlated with narrow urethral plate, a similar to [20]. While, Aboutaleb reported higher incidence in fistula in patients with narrow urethral plates when compared to those with wide urethral plate [6-21]. Though this study was a prospective study, it was limited by a small sample size that hindered the significant statistical difference detection in complications. Moreover, single surgeon series cannot be generalized as the outcome of repair, including complications, may be related to the skill of the surgeon.

\section{Conclusion}

The pre-incision urethral plate width and granular width was not correlated with the TIP outcome. A better HOPE score is associated with wide urethral plate. However, the width of the urethral plate and glanular width may predict the functional outcome (urinary stream).

\section{Acknowledgment}

None.

\section{Conflict of interest}

No conflict of interest.

\section{References}

1. Silay MS, Sirin H, Tepeler A, Karatag T, Armagan A, et al. ( 2012) Snodgraft technique for the treatment of primary distal hypospadias: pushing the envelope. The Journal of urology 188(3): 938-942.

2. Wilkinson DJ, Farrelly P, Kenny SE (2012) Outcomes in distal hypospadias: a systematic review of the Mathieu and tubularized incised plate repairs. Journal of pediatric urology 8(3): 307-312.

3. Arlen AM, Kirsch AJ, Leong T, Broecker BH, Smith EA, et al. (2015) Further analysis of the Glans-Urethral Meatus-Shaft (GMS) hypospadias score: correlation with postoperative complications. Journal of pediatric urology 11(2): 71.e1-e5.

4. Holland AJ, Smith GH (2000) Effect of the depth and width of the urethral plate on tubularized incised plate urethroplasty. The Journal of urology 164(2): 489-491.

5. Merriman LS, Arlen AM, Broecker BH, Smith EA, Kirsch AJ, et al. (2013) The GMS hypospadias score: assessment of inter-observer reliability and correlation with post-operative complications. Journal of pediatric urology 9(6 Pt A): 707-712.

6. Aboutaleb H (2014) Role of the urethral plate characters in the success of tubularized incised plate urethroplasty. Indian journal of plastic surgery : official publication of the Association of Plastic Surgeons of India 47(2): 227-231.
7. Bush NC, Snodgrass W (2017) Pre-incision urethral plate width does not impact short-term Tubularized Incised Plate urethroplasty outcomes. Journal of pediatric urology 13(6): 625.e1-.e6.

8. Bush NC, Villanueva C, Snodgrass W (2015) Glans size is an independent risk factor for urethroplasty complications after hypospadias repair. Journal of pediatric urology 11(6): 355.e1-e5.

9. Nguyen MT, Snodgrass WT, Zaontz MR (2004) Effect of urethral plate characteristics on tubularized incised plate urethroplasty. The Journal of urology 171(3): 1260-1262.

10. Bush NC, DaJusta D, Snodgrass WT (2013) Glans penis width in patients with hypospadias compared to healthy controls. Journal of pediatric urology 9(6 Pt B): 1188-1191.

11. van der Toorn F, de Jong TP, de Gier RP, Callewaert PR, van der Horst $\mathrm{EH}$, et al. (2013) Introducing the HOPE (Hypospadias Objective Penile Evaluation)-score: a validation study of an objective scoring system for evaluating cosmetic appearance in hypospadias patients. Journal of pediatric urology 9(6 Pt B): 1006-1016.

12. Stein DM, Thum DJ, Barbagli G, Kulkarni S, Sansalone S, et al. (2013) A geographic analysis of male urethral stricture aetiology and location. BJU international 112(6): 830-834.

13. Moriya K, Kakizaki H, Tanaka H, Furuno T, Higashiyama H, et al. (2006) Long-term cosmetic and sexual outcome of hypospadias surgery: norm related study in adolescence. The Journal of urology 176(4 Pt 2):18891892.

14. Eassa W, He X, El-Sherbiny M (2011) How much does the midline incision add to urethral diameter after tubularized incised plate urethroplasty? An experimental animal study. The Journal of urology 186(4 Suppl): 1625-1629.

15. da Silva EA, Lobountchenko T, Marun MN, Rondon A, Damião R (2014) Role of penile biometric characteristics on surgical outcome of hypospadias repair. Pediatric surgery international 30(3): 339-344.

16. Chukwubuike KE, Obianyo NEN, Ekenze SO, Ezomike UO (2019) Assessment of the effect of urethral plate width on outcome of hypospadias repair. Journal of pediatric urology 15(6): 627.e1-e6.

17. Mane S, Arlikar J, Dhende N (2013) Modified tubularized incised plate urethroplasty. Journal of Indian Association of Pediatric Surgeons 18(2): 62-65.

18. Eliçevik M, Tireli G, Demirali O, Unal M, Sander S (2007) Tubularized incised plate urethroplasty for hypospadias reoperations in 100 patients. International urology and nephrology 39(3): 823-827.

19. Sarhan O, Saad M, Helmy T, Hafez A (2009) Effect of suturing technique and urethral plate characteristics on complication rate following hypospadias repair: a prospective randomized study. The Journal of urology 182(2): 682-685.

20. Bhat A, Mandal AK (2008) Acute postoperative complications of hypospadias repair. Indian journal of urology : IJU : journal of the Urological Society of India 24(2): 241-248.

21. Shapiro SR (1984) Complications of hypospadias repair. The Journal of urology 131(3): 518-522. 